\title{
Conformal Array Pattern Synthesis and Activated Elements Selection Strategy Based on PSOGSA Algorithm
}

\author{
Bin Sun, ${ }^{1}$ Chunheng Liu, ${ }^{2}$ Yang Liu, ${ }^{2}$ Xiaofang Wu, ${ }^{2}$ Yongzhen Li, ${ }^{1}$ and Xuesong Wang ${ }^{1}$ \\ ${ }^{1}$ State Key Laboratory of Complex Electromagnetic Environment Effects on Electronics and Information System, \\ National University of Defense Technology, Changsha 410073, China \\ ${ }^{2}$ Northern Institute of Electronic Equipment of China, Beijing 100083, China
}

Correspondence should be addressed to Bin Sun; victor20140818@126.com

Received 1 April 2015; Accepted 16 June 2015

Academic Editor: Kerim Guney

Copyright (C) 2015 Bin Sun et al. This is an open access article distributed under the Creative Commons Attribution License, which permits unrestricted use, distribution, and reproduction in any medium, provided the original work is properly cited.

\begin{abstract}
The pattern synthesis and activated element selection for conformal array is investigated based on hybrid particle swarm optimization-gravitational search algorithm (PSOGSA) in this paper. With the introduction of PSOGSA algorithm which is a novel hybrid optimization technique, the element excitations are optimized to obtain the desired pattern for conformal array in the case of considering uncoupled and coupled element pattern. Numerical simulation and full-wave electromagnetic calculation verify the advantage and efficiency of our method. Then, a novel strategy of activated element selection based on PSOGSA algorithm is proposed for saving the energy consumption in conformal array.
\end{abstract}

\section{Introduction}

Conformal antenna, due to its wide range of scan angle and little influence on aerodynamic performance of the aerial vehicle, is vastly used in radar, communication, navigation, and remote sensing system [1]. In the past years, antenna pattern synthesis has been an attractive research topic in the antenna community. Many classical synthesis methods of linear and planar array can not be applied to conformal array, since the pattern synthesis of conformal array can not be directly deduced from the product of element factor and array factor. Until now, many iterative numerical computing techniques have been done focusing on the pattern synthesis method for conformal array, such as intersection projector method (APM) [2, 3], least mean square (LMS) [4, 5], and adaptive array method [6].

Intellectual evolutionary optimization algorithms are proved to be effective in solving antenna array pattern synthesis problems, because of high robust performance and effective search ability. Many algorithms have been proposed and applied to conformal array synthesis, such as genetic algorithm (GA) $[7,8]$, simulated annealing algorithm (SA) [9, 10], particle swarm optimization algorithm (PSO) [11, 12], differential evolution algorithm (DE) [13], and Invasive Weed Optimization (IWO) [14]. However, the above independent algorithm often shows some drawbacks of complex operation, locally convergence or slow convergence speed. Recently, several hybrid algorithms have been proposed for conformal array design, which inherits advantages from its constituent algorithm, could overcome the drawbacks, and has more powerful search ability, for example, hybrid IGAIPSO algorithm [15] and hybrid IWOPSO algorithm [16]. However, these algorithms scarcely consider the mutual coupling effect, which is a significant factor in the practical pattern synthesis for antenna array. They also did not dispose element selection problem for low hardware and energy consumption.

In this paper, we introduce the PSOGSA algorithm into the pattern synthesis with and without coupled element pattern for conformal array. Moreover, a novel antenna element selection strategy is proposed based on PSOGSA algorithm.

Gravitational search algorithm (GSA) is a novel optimization computing technique based on the basic principle of the Newton's law, first proposed by Rashedi et al. [17]. Then, by combining the ability of exploration in GSA algorithm and the ability of exploration in PSO algorithm, Seydali and Siti 


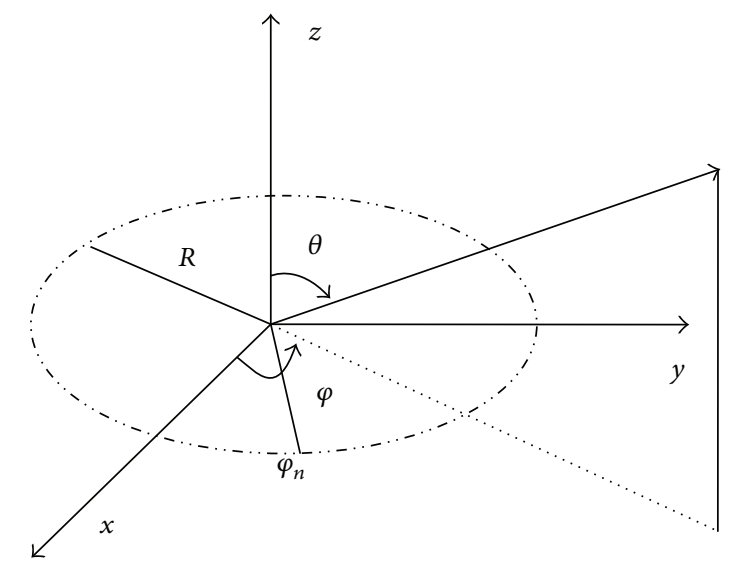

FIgURE 1: Far field coordinates for the circle array antenna.

developed the hybrid PSOGSA algorithm [18], which shows a better ability to find global optimum with fast convergence and be applied in many fields [19].

The remaining sections of this paper are organized as follows. The pattern synthesis model and its cost function for conformal array are present in Section 2. The principle of PSOGSA is present in Section 3. Numerical comparison and full-wave calculation for conformal array pattern synthesis are addressed in Section 4. Conformal array element selection strategy is addressed in Section 5. Finally, brief conclusions are discussed in Section 6.

\section{Conformal Antenna Array Pattern Synthesis}

Let us consider a circular antenna array composed of $N$ elements shown in Figure 1, in which the far field radiation pattern can be expressed as

$$
\begin{gathered}
F\left(\theta, \varphi, \theta_{0}, \varphi_{0}\right)=\sum_{n=0}^{N-1} A_{n} \cdot f_{n}(\theta, \varphi) \\
\cdot e^{j(2 \pi / \lambda) R\left[\sin \theta \cos \left(\varphi-\varphi_{n}\right)-\sin \theta_{0} \cos \left(\varphi_{0}-\varphi_{n}\right)\right]},
\end{gathered}
$$

where $R$ is the circular radius, $\theta_{0}$ and $\varphi_{0}$ are the direction of the main beam in elevation and azimuth angle, and $f_{n}(\theta, \varphi)$ is the element pattern. $A_{n}=a_{n} e^{j \phi_{n}}$, and $a_{n}$ and $\phi_{n}$ are the amplitude and phase of the excitation coefficient, respectively.

The goal of the pattern synthesis for conformal array is to optimize the element excitations for minimizing the difference between the synthesized maximum side lobe level $\left(\mathrm{MSLL}_{\mathrm{syn}}\right)$ and the desired maximum side lobe level $\left(M_{S L L} L_{\text {desired }}\right)$ under certain main lobe first null beam width (FNBW). Thus, the cost function defined in this paper is the absolute values of excess between the synthesized $\mathrm{MSLL}_{\text {syn }}$ and the desired $\mathrm{MSLL}_{\text {desired }}$ under the FNBW constraint as follows:

$\min . \quad C=\|\left|\operatorname{MSLL}_{\text {syn }}\right|-\left|\operatorname{MSLL}_{\text {desired }}\right| \mid$

s.t. $\quad \mathrm{FNBW}=\Phi_{\mathrm{FNBW}}$.

\section{Hybrid PSOGSA Algorithm and Its Numerical Simulation}

3.1. Hybrid PSOGSA Algorithm. In this part, hybrid PSOGSA algorithm is introduced and applied in the pattern synthesis of conformal array. The hybrid algorithm mainly integrates the ability of exploration in PSO algorithm and the ability of exploration in GSA algorithm to find optimum solution more efficiently, which has a better balance between the ability of exploitation and exploration efficiently to find the global optimum. The process of the hybrid algorithm is formulated in detail as follows [18].

Step 1 (initiate all the agents randomly). Suppose a system with $N$ agents; the algorithm starts with randomly placing all agents in search space.

Step 2 (evaluate the fitness value for each agent). All the agents are ranked based on their fitness. The $g_{\text {best }}$ is the agent with the best fitness value.

Step 3 (computing the gravitational force and $G(t)$ ). The gravitational forces from agent $j$ on agent $i$ at a specific time $t$, is defined as follows:

$$
F_{i j}^{d}(t)=G(t) \frac{M_{p i}(t) \times M_{a j}(t)}{R_{i j}(t)+\varepsilon}\left(x_{j}^{d}(t)-x_{i}^{d}(t)\right),
$$

where $M_{a j}(t)$ is the active gravitational mass related to agent $j, M_{p i}(t)$ is the passive gravitational mass related to agent $i, \varepsilon$ is a small constant, $G(t)$ is the gravitational constant at time $t$, and $R_{i j}(t)$ is the Euclidian distance between two agents $i$ and $j$ :

$$
R_{i j}(t)=\left\|X_{i}(t), X_{j}(t)\right\|_{2} .
$$

$G(t)$ is calculated as

$$
G(t)=G_{0} \times \exp \left(-\alpha \times \frac{\text { iter }}{\text { max iter }}\right),
$$

where $\alpha$ and $G_{0}$ are descending coefficient and initial value respectively, iter is the current iteration, and max iter is the maximum number of iterations.

Step 4 (the masses and total force computation). Inertial masses are calculated according their fitness value, as follows:

$$
\begin{aligned}
M_{a i} & =M_{p i}=M_{i i}=M_{i}, \quad i=1,2, \ldots, N, \\
m_{i}(t) & =\frac{\text { fit }_{i}(t)-\operatorname{worst}(t)}{\operatorname{best}(t)-\operatorname{worst}(t)}, \\
M_{i}(t) & =\frac{m_{i}(t)}{\sum_{j=1}^{N} m_{j}(t)},
\end{aligned}
$$

where $\mathrm{fit}_{i}(t)$ is the fitness of agent $i$ at time $t$.

For a minimization problem, worst $(t)$ and best $(t)$ are defined as follows:

$$
\begin{aligned}
\text { best }(t) & =\min _{j \in\{1,2, \ldots, N\}} \mathrm{fit}_{j}(t), \\
\text { worst }(t) & =\max _{j \in\{1,2, \ldots, N\}} \mathrm{fit}_{j}(t) .
\end{aligned}
$$


For a maximization problem, worst $(t)$ and best $(t)$ are defined as follows:

$$
\begin{aligned}
\operatorname{best}(t) & =\max _{j \in\{1,2, \ldots, N\}} \mathrm{fit}_{j}(t), \\
\operatorname{worst}(t) & =\min _{j \in\{1,2, \ldots, N\}} \mathrm{fit}_{j}(t) .
\end{aligned}
$$

If the dimension of the problem is $d$, the total force that acts on agent $i$ is calculated as the following equation:

$$
F_{i}^{d}(t)=\sum_{j=1, j \neq i}^{N} \operatorname{rand}_{j} F_{i j}^{d}(t),
$$

where $\operatorname{rand}_{j}$ is a random number in the interval $[0,1]$.

Step 5. According to the law of motion, the acceleration of an agent is proportional to the result force and inverse to its mass; therefore, the acceleration of all agents is defined as follows:

$$
a_{i}^{d}(t)=\frac{F_{i}^{d}(t)}{M_{i}(t)}
$$

where $M_{i}(t)$ is the mass of object $i$.

Step 6. The velocity and position of agents are calculated as follow:

$$
\begin{aligned}
v_{i}^{d}(t+1)= & \operatorname{rand}_{i} \times v_{i}^{d}(t)+c_{1} \times \operatorname{rand} \times a_{i}^{d}(t)+c_{2} \\
& \times \operatorname{rand} \times\left(g_{\text {best }}-x_{i}^{d}(t)\right), \\
x_{i}^{d}(t+1)= & x_{i}^{d}(t)+v_{i}^{d}(t+1) .
\end{aligned}
$$

Step 7. Renew the fitness value for all agents. The fitness values of renewed agents are calculated; then, process returns to Step 2, repeated until either the maximum number of iteration is reached or the fitness is met.

The hybrid algorithm flow chart is summarized as in Figure 2.

3.2. Numerical Results Based on Benchmark Functions. In order to show the efficiency PSOGSA algorithm, some tests are executed as follows. A typical bench mark function is applied to compare the efficiency between hybrid and single algorithm:

$$
f(x)=\frac{1}{4000} \sum_{i=1}^{n} x_{i}^{2}-\prod_{i=1}^{n} \cos \left(\frac{x_{i}}{\sqrt{i}}\right)+1
$$

where $f(x)$ has an amount of local minima and a global minimum zero. It is a tough work to solve the multimodal optimization problem, and the above function is a good one to test the efficiency of proposed algorithm.

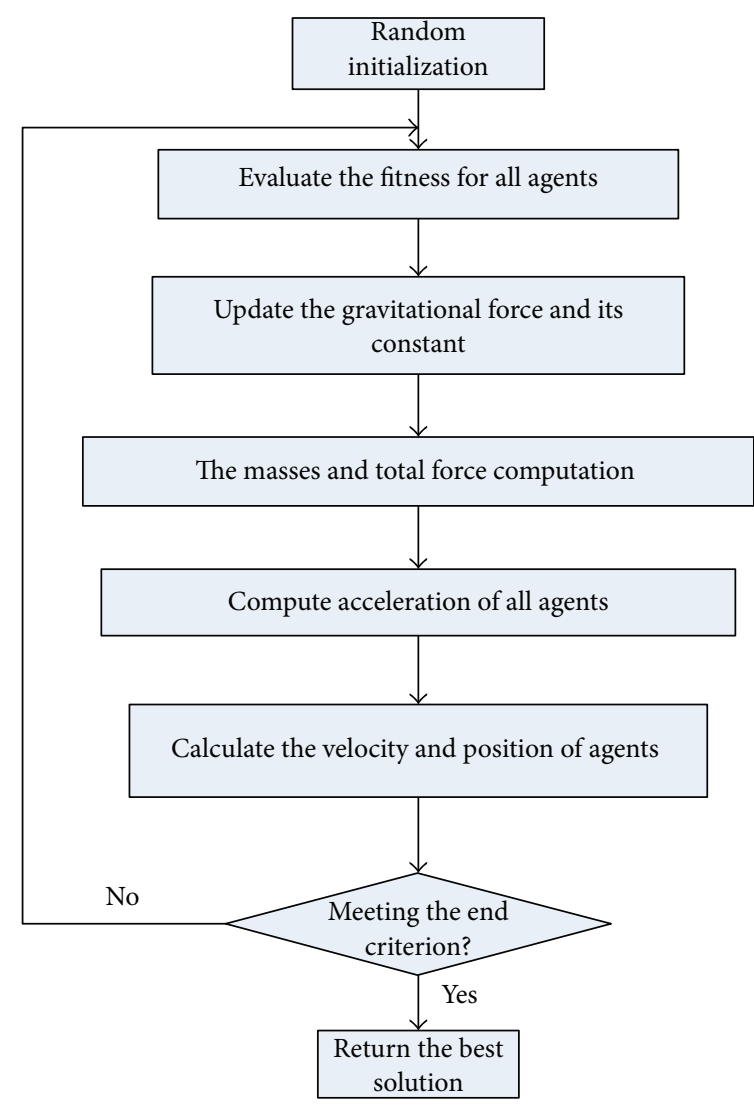

FIGURE 2: Hybrid PSOGSA algorithm flow chart.

TABLE 1: Parameters value of PSO, GSA, and PSOGSA.

\begin{tabular}{lccc}
\hline Parameters & PSO & GSA & PSOGSA \\
\hline iter $_{\max }$ & 1000 & 1000 & 1000 \\
$\operatorname{dim}$ & 30 & 30 & 30 \\
$P_{\max }$ & 40 & - & 40 \\
$x_{\text {ini }}$ & {$[-100,100]$} & {$[-100,100]$} & {$[-100,100]$} \\
$c_{1}$ & 2 & - & 2 \\
$c_{2}$ & 2 & - & 2 \\
$w_{\max }$ & 0.9 & - & 0.9 \\
$w_{\min }$ & 0.4 & - & 0.4 \\
\hline
\end{tabular}

The optimized parameters are configured as Table 1.

Figure 3 presents the simulation of three algorithms, which show that the hybrid algorithm is superior to the single algorithm. The hybrid has a better balance between the ability of globe exploration and local exploitation, which could avoid trapping in local minima and capable of enhanced search ability.

\section{Application of Hybrid PSOGSA Algorithm in Conformal Array}

4.1. Circular Array Pattern Synthesis without Mutual Coupling Effect. Now consider a half-circular conformal array consisting of 25 elements as shown in Figure 4(a), in which 


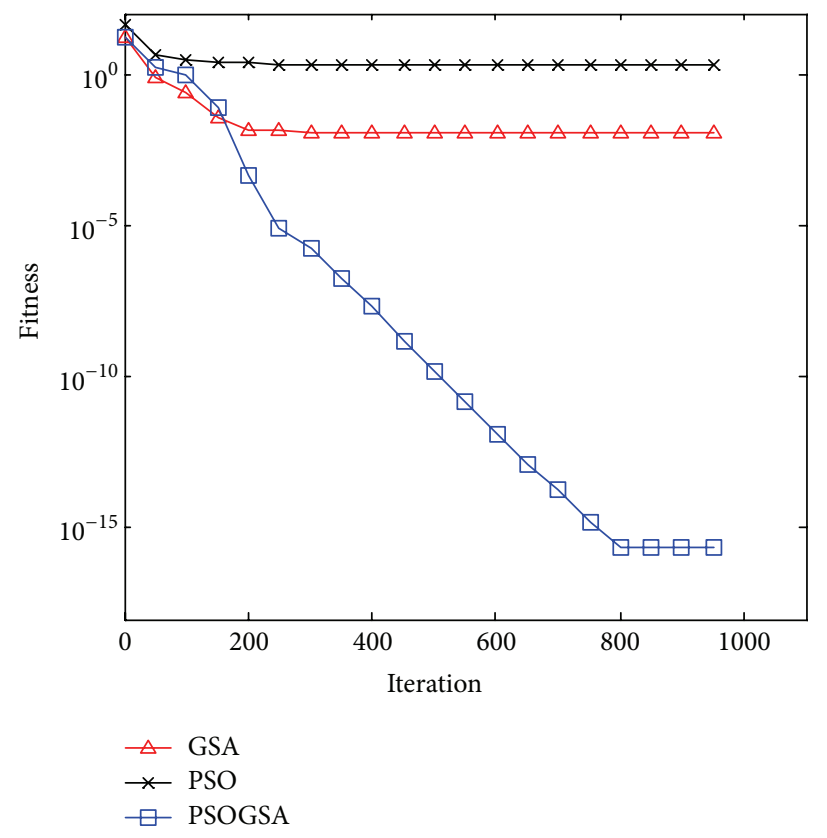

FIgURE 3: Testing results of Rastrigin function.

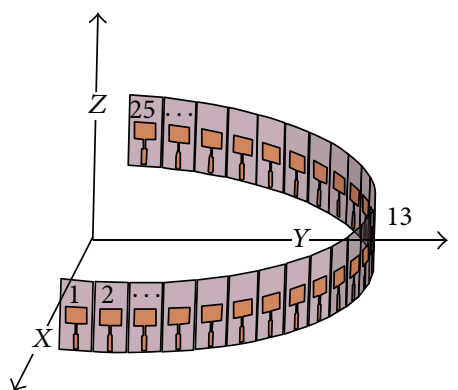

(a)

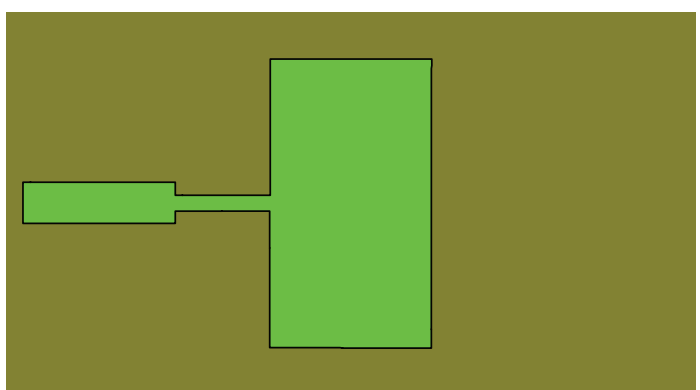

(b)

Figure 4: (a) Half-circular array antenna. (b) Microstrip patch antenna.

all elements located along the circular arc with the radius $R=12 \lambda / \pi$. The arc distance between neighbor elements is $\lambda / 2$.

The conformal element antenna is microstrip patch antenna, which has a center frequency of $5 \mathrm{GHz}$ and a bandwidth exceeding $10 \%$ for return loss less than $-10 \mathrm{~dB}$ shown in Figure 4(b). The pattern is shown in Figure 5(a) calculated via Ansoft HFSS. The unsynthesized pattern of conformal array is presented in Figure 5(b) without considering the mutual coupling effect.

The desired pattern mask is set as follows. The main lobe range is in $\varphi_{M} \in\left[78^{\circ}, 102^{\circ}\right]$, and $\mathrm{MSLL}_{\text {desired }}$ is set $-28 \mathrm{~dB}$. The parameters of optimization algorithms are set in Table 2.

The array pattern is synthesized by PSO [11], GSA [17], IWOPSO [16], and PSOGSA algorithm, respectively. After running 1000 times iteration and 10 independent experiments, the average element antenna excitation amplitudes are obtained in Figure 6. Apparently, the amplitude for PSOGSA algorithm is smoother than the other algorithms.
The average convergence curves of cost function value for all algorithms are illustrated in Figure 7(a), which indicates that the cost of PSOGSA has the lowest absolute error between the synthesized $M_{S L L}$ syn and the desired MSLL $L_{\text {desired }}$ compared with the other algorithms. Figure 7(b) presents the synthesized array radiation pattern for circular array based on all algorithms. As shown in the figure, the $\mathrm{MSLL}_{\text {syn }}$ of PSOGSA algorithm is $-27.5 \mathrm{~dB}$, the MSLL $_{\text {syn }}$ of PSO is $-26.9 \mathrm{~dB}$, the $\mathrm{MSLL}_{\text {syn }}$ of GSA is $-27.19 \mathrm{~dB}$, and the $\mathrm{MSLL}_{\text {syn }}$ of IWOPSO is $-27.18 \mathrm{~dB}$. Thus, PSOGSA algorithm is the most advantageous compared with the other algorithms in the synthesized pattern.

4.2. Circular Array Pattern Synthesis with Coupled Element Pattern. In order to obtain the practical pattern of the conformal antenna array, mutual coupling effect has to be considered. Here, 13th element located at $\varphi=90^{\circ}$ is selected as the representation of the coupled element pattern. The full-wave calculation result via Ansoft HFSS is show in Figure 8(a). 
TABle 2: Parameter setting for each algorithm.

\begin{tabular}{|c|c|c|c|c|c|c|c|}
\hline \multicolumn{2}{|c|}{ PSO } & \multicolumn{2}{|c|}{ GSA } & \multicolumn{2}{|c|}{ IWOPSO } & \multicolumn{2}{|c|}{ PSOGSA } \\
\hline Param. & Val. & Param. & Val. & Param. & Val. & Param. & Val. \\
\hline Pop_size & 100 & Pop_size & 100 & Pop_size & 100 & Pop_size & 100 \\
\hline$C_{1}$ & 2 & $G_{0}$ & 1 & Initial_SD & 100 & $C_{1}$ & 2 \\
\hline$C_{2}$ & 2 & - & - & Final_SD & 0.005 & $C_{2}$ & 2 \\
\hline- & - & - & - & $s \_$max & 5 & $G_{0}$ & 1 \\
\hline- & - & - & - & $s_{-} \min$ & 2 & - & - \\
\hline - & - & - & - & $C_{1}=C_{2}$ & 2 & - & - \\
\hline
\end{tabular}

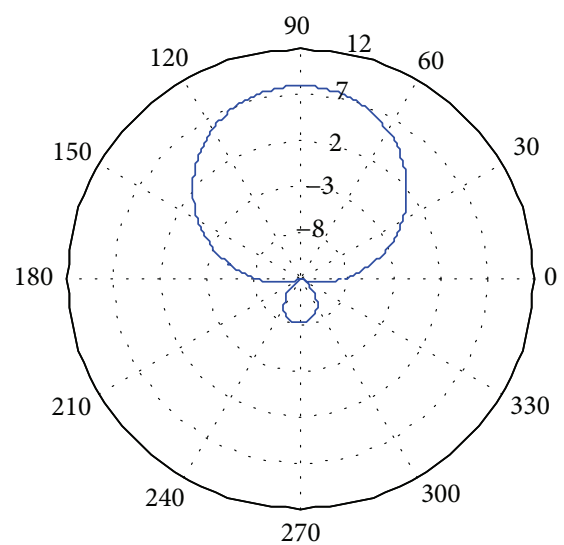

(a)

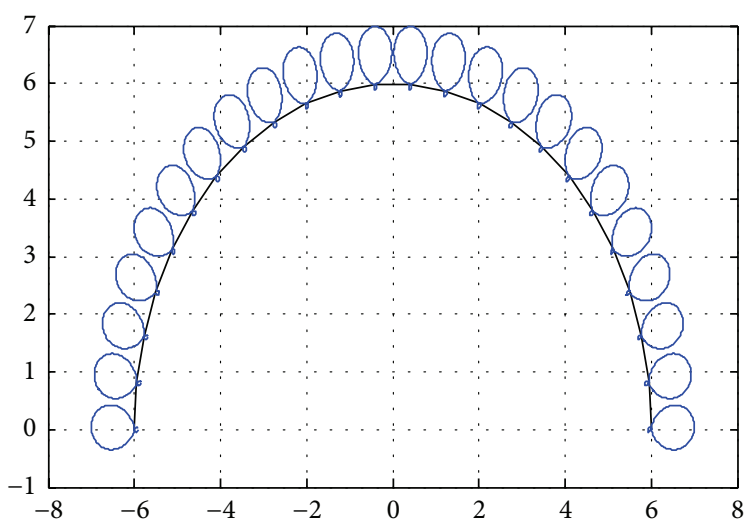

(b)

Figure 5: (a) Element antenna pattern (dB). (b) conformal array pattern.

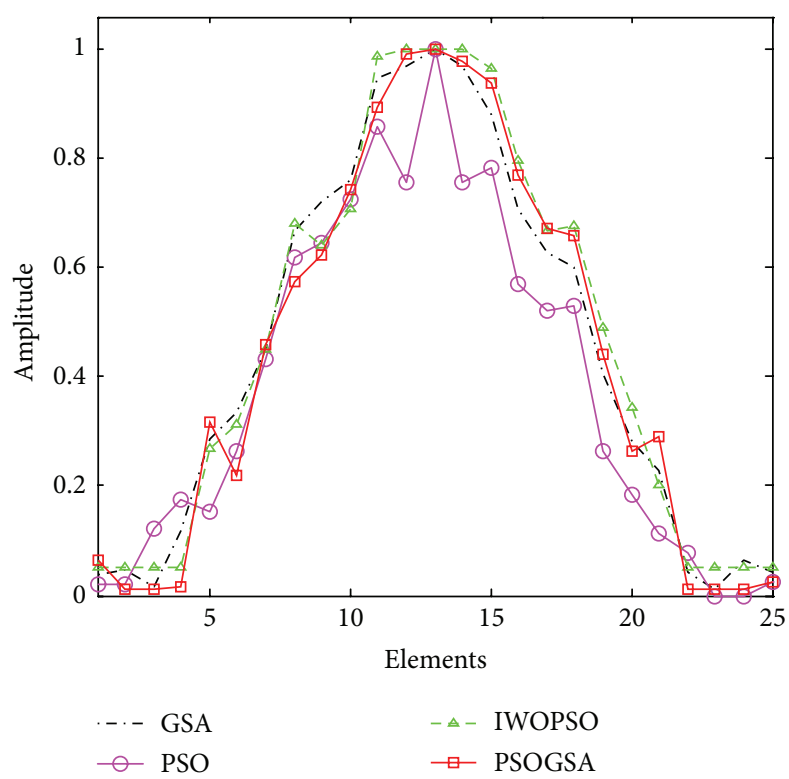

FIGURE 6: Element amplitude distribution for half-circle array.

Compared with Figure 5(a), the mutual coupling effect makes the element antenna pattern gain decrease and main lobe with ripples and back lobe level increase as shown in Figure 8(a). And the whole conformal array pattern consisting of the coupled element pattern is present in Figure 8(b).
By considering mutual coupling effect, the desired MSLL $_{\text {desired }}$ is modified as $-21 \mathrm{~dB}$; the main lobe is in $\varphi_{M} \in$ $\left[78^{\circ}, 102^{\circ}\right]$. With the same array configuration as in Figure 4, the array pattern was synthesized using coupled element pattern based on PSOGSA algorithm. 


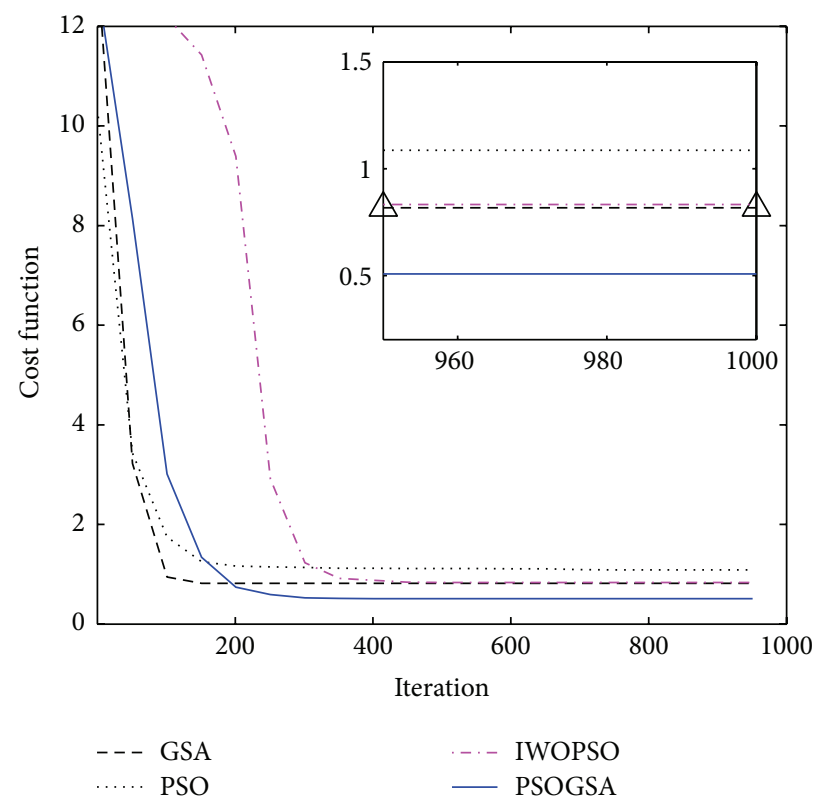

(a)

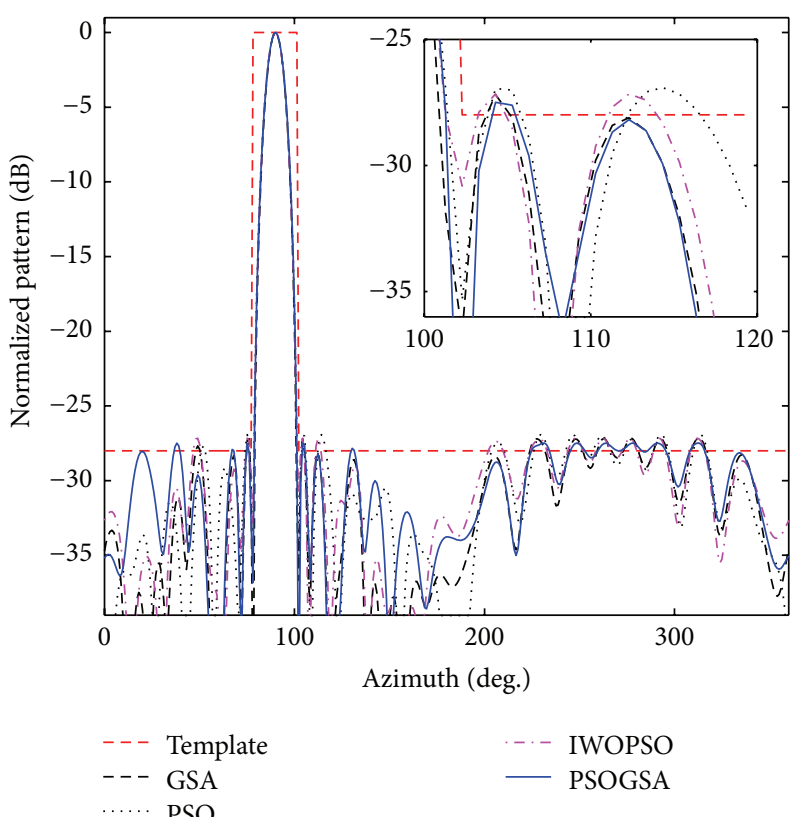

(b)

Figure 7: (a) Cost function versus iteration times. (b) Radiation pattern for half-circle array.

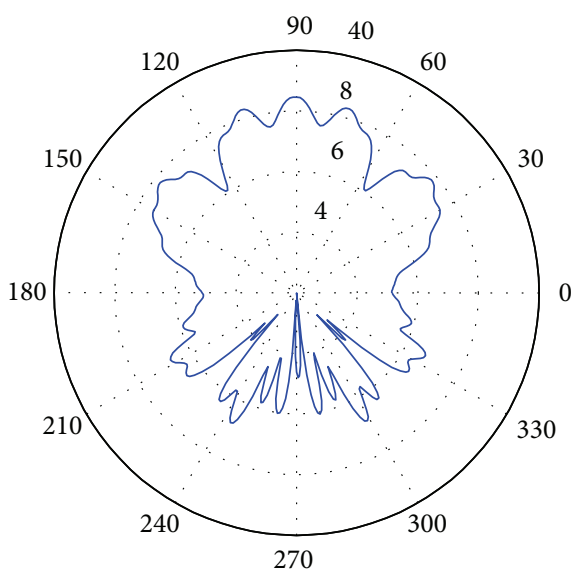

(a)

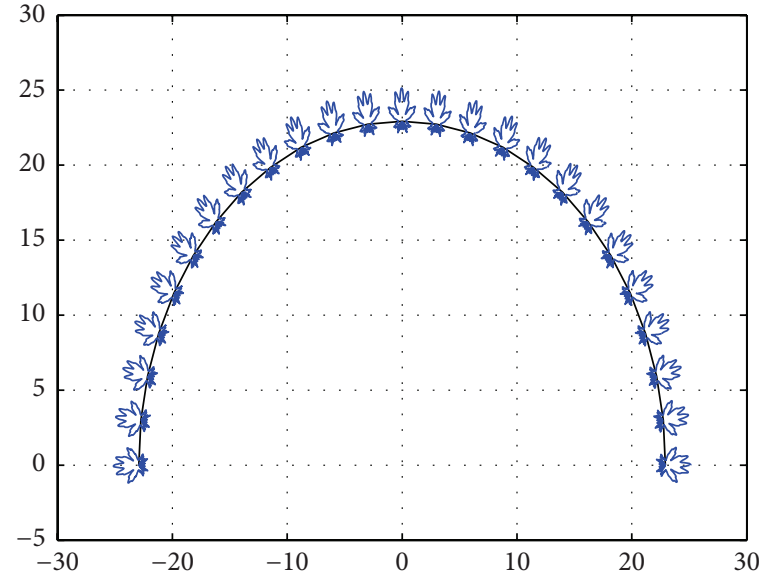

(b)

Figure 8: (a) Embedded element antenna pattern for 13th element. (b) Simulating each element pattern under coupling effect.

After the PSOGSA optimization, the excitation amplitude and phase obtained in coupled situation are shown in Table 3.

The average convergence curves of the cost function derived from GSA, IWOPSO, and PSOGSA algorithm are illustrated in Figure 9(a), and the array pattern synthesized with the coupled element pattern is shown in Figure 9(b).

According to Figure 9(a), it is indicated that PSOGSA algorithm has the lowest absolute error between the synthesized MSLL $_{\text {syn }}$ and the desired MSLL ${ }_{\text {desired. }}$. According to Figure 9(b), the MSLL $_{\text {syn }}$ of PSOGSA algorithm is $-20.0 \mathrm{~dB}$, the $\mathrm{MSLL}_{\text {syn }}$ of PSO is $-19.6 \mathrm{~dB}$, the $\mathrm{MSLL}_{\text {syn }}$ of GSA is
$-19.7 \mathrm{~dB}$, and the $\mathrm{MSLL}_{\text {syn }}$ of IWOPSO is $-19.8 \mathrm{~dB}$. Thus, PSOGSA algorithm is the most advantageous compared with the other algorithms in the synthesized pattern. In addition, the mutual coupling effect makes the MSLL $\mathrm{syn}_{\text {increase about }}$ $7 \mathrm{~dB}$ compared with Figure $7(\mathrm{~b})$.

4.3. Full-Wave Simulation Experiment via Ansoft HFSS. To further more testify the validation of PSOGSA in conformal array pattern synthesis, full-wave electromagnetic calculation is executed via Ansoft HFSS. The result of electromagnetic calculation is nearly the same as numerical simulation using 


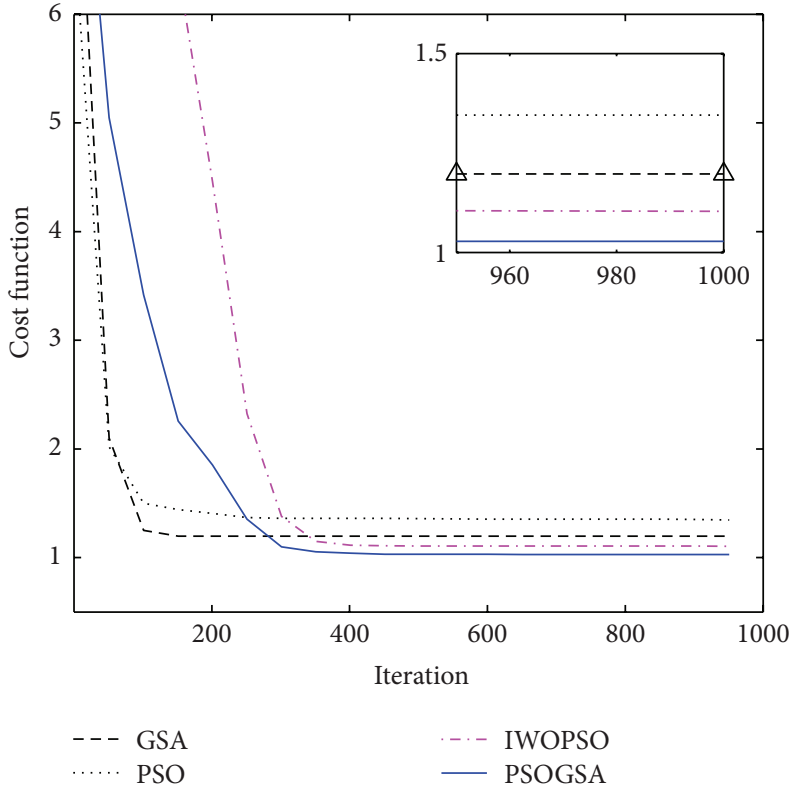

(a)

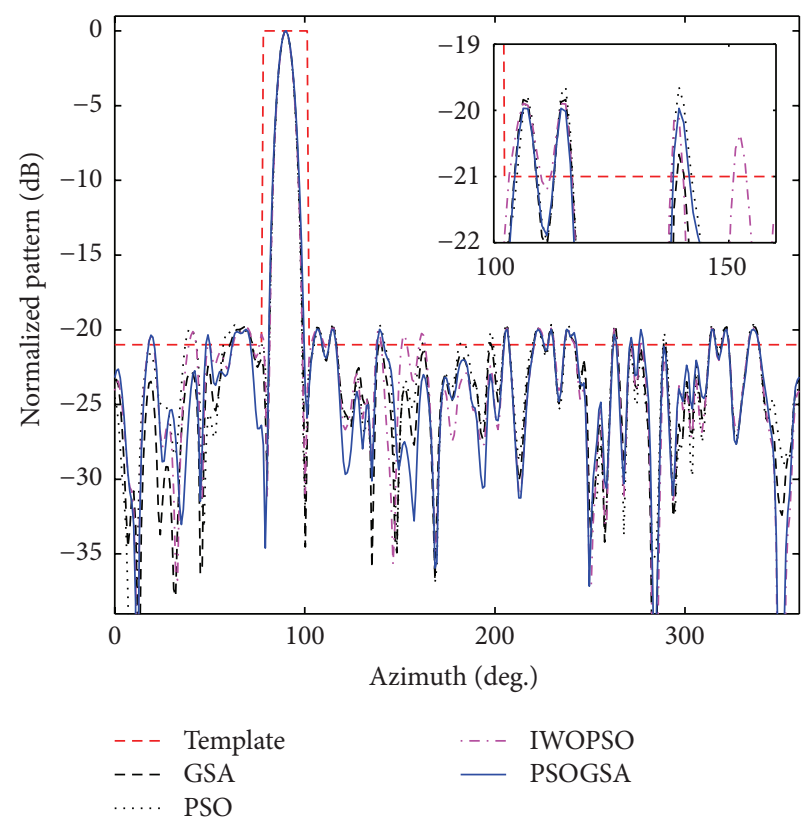

(b)

FIGURE 9: (a) Cost function versus iteration times with coupled pattern. (b) Radiation pattern for the half-circular array with coupled pattern.

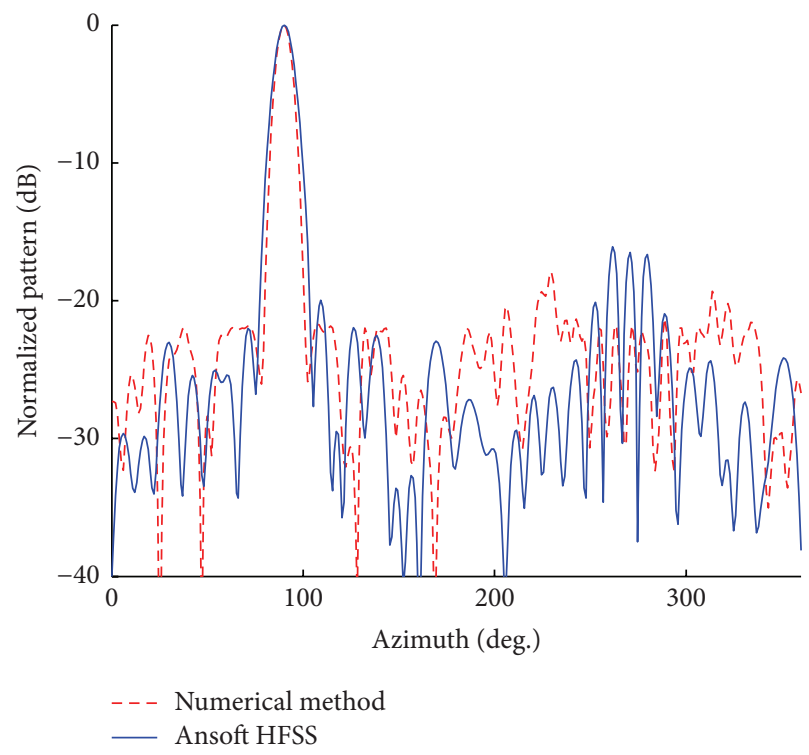

(a)

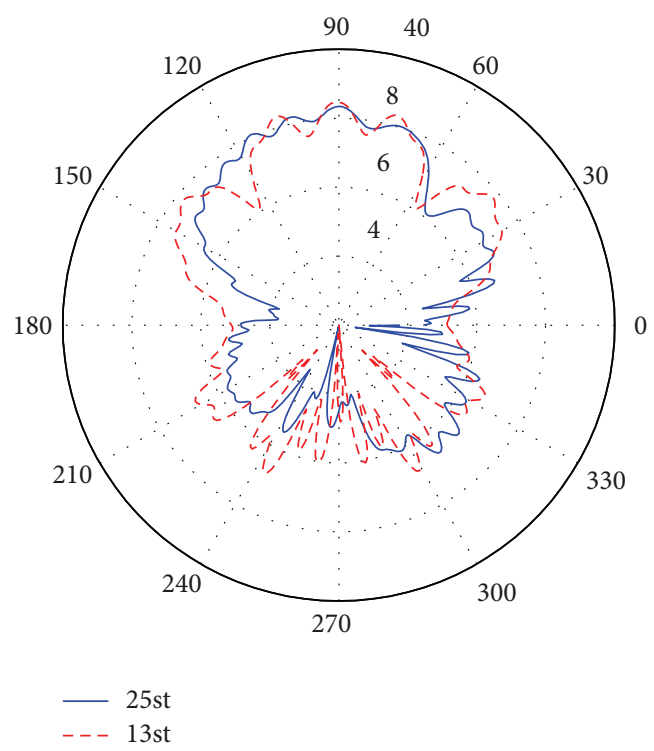

(b)

FIgure 10: (a) Comparison from Ansoft HFSS and numerical simulation. (b) Difference between 13th and 25th pattern.

the excitations from Table 3 according to Figure 10(a), which demonstrates the efficiency and accuracy of the PSOGSA algorithm. The little difference between Ansoft HFSS calculation and numerical method is due to the element pattern difference. Clearly, the patterns of 13th element and the 25th element are not the same as shown in Figure 10(b). The 13th element is coupled with two-side 12 elements; however, the 25th element is coupled mostly with the right side 12 elements. We have neglected this when synthesizing the array antenna pattern using PSOGSA algorithm and just consider all element pattern the same as 13th element.

\section{The Strategy of the Active Elements Selection for Conformal Array Antenna}

5.1. Active Elements Selection Strategy. For beam scanning angle is specified, only parts of elements make great contribution to the pattern synthesis, and the others contribute so 


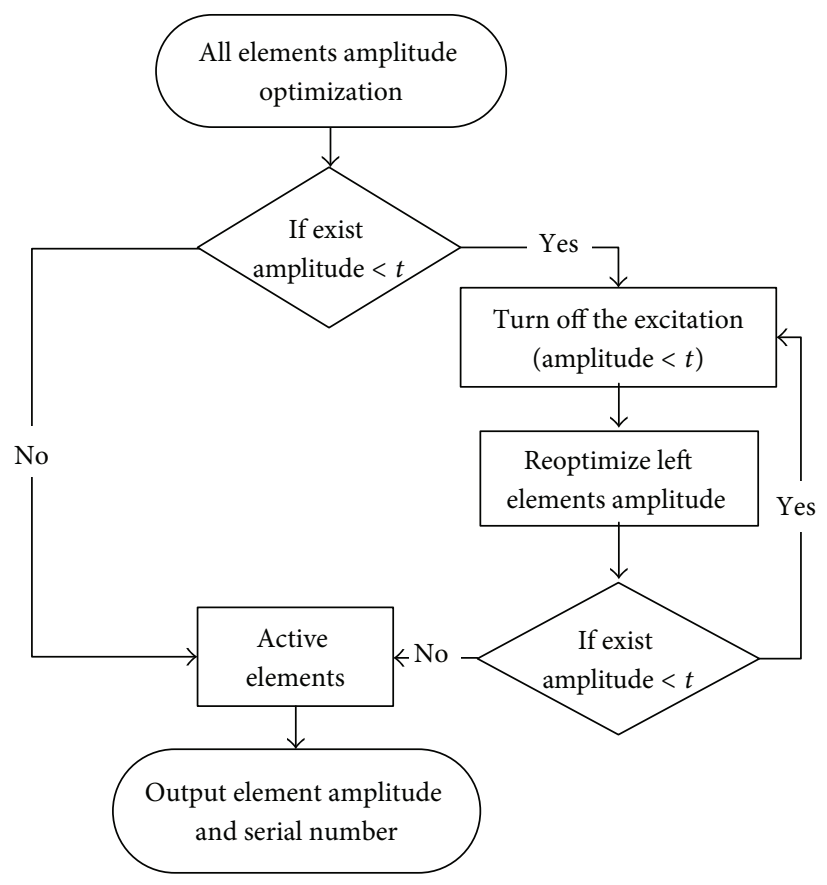

FIGURE 11: Element selection strategy.

TABLE 3: Each element amplitude and phase derived from MGSAPSO.

\begin{tabular}{|c|c|c|}
\hline Element sequence & Amplitude & Phase \\
\hline 1 & 0.0937 & 360.0000 \\
\hline 2 & 0.0456 & 180.4226 \\
\hline 3 & 0.0010 & 3.9177 \\
\hline 4 & 0.1105 & 193.5056 \\
\hline 5 & 0.3185 & 32.1019 \\
\hline 6 & 0.1103 & 242.4684 \\
\hline 7 & 0.2314 & 107.1652 \\
\hline 8 & 0.4748 & 348.5075 \\
\hline 9 & 0.5022 & 248.5256 \\
\hline 10 & 0.4412 & 168.9301 \\
\hline 11 & 0.7887 & 111.0829 \\
\hline 12 & 0.5743 & 75.9739 \\
\hline 13 & 0.9999 & 64.2038 \\
\hline 14 & 0.7664 & 75.9739 \\
\hline 15 & 0.7340 & 111.0829 \\
\hline 16 & 0.7172 & 168.9301 \\
\hline 17 & 0.5780 & 248.5256 \\
\hline 18 & 0.4458 & 348.5075 \\
\hline 19 & 0.3180 & 107.1652 \\
\hline 20 & 0.2627 & 242.4684 \\
\hline 21 & 0.2734 & 32.1019 \\
\hline 22 & 0.0011 & 193.5056 \\
\hline 23 & 0.0703 & 3.9177 \\
\hline 24 & 0.0010 & 180.4226 \\
\hline 25 & 0.0414 & 360.0000 \\
\hline
\end{tabular}

little that can be neglected. In this situation, the strategy of selecting active elements becomes a crucial issue.

In this paper, a novel strategy is proposed for active elements selection based on PSOGSA algorithm, which is shown in Figure 11.

Step 1. Firstly, all the elements are optimized to synthesize the desired array pattern using PSOGSA algorithm. Then, the normalization is performed for each element. Turn off the element excitations whose coefficients are smaller than $t(0 \leq t \leq 1)$, and keep the other element excitation activated.

Step 2. For the active elements from Step 1, reoptimize the element excitation for the desired pattern and renormalization. Remove the excitation whose coefficient is below $t$ and save the others.

Step 3. Repeat Steps 1 and 2 until all the remainder excitation coefficients are bigger than $t$ or reach the specified least element number.

Now the conformal array configured as Figure 4 is used to illustrate the performance of our active elements selection strategy. For practical phased antenna array, several scan angles should be formed; however, we only take $\varphi=90^{\circ}$ as design example. Let $t=0.1$; the beam pattern is synthesized with the strategy proposed, and the entire optimization progress is as Table 4 .

The active elements of each step are shown in Figure 12.

Figure 13(a) presents the pattern synthesized result by weight (1), weight (3), and weight (5) based on PSOGSA algorithm. Apparently, the patterns obtained from 25 elements, 17 


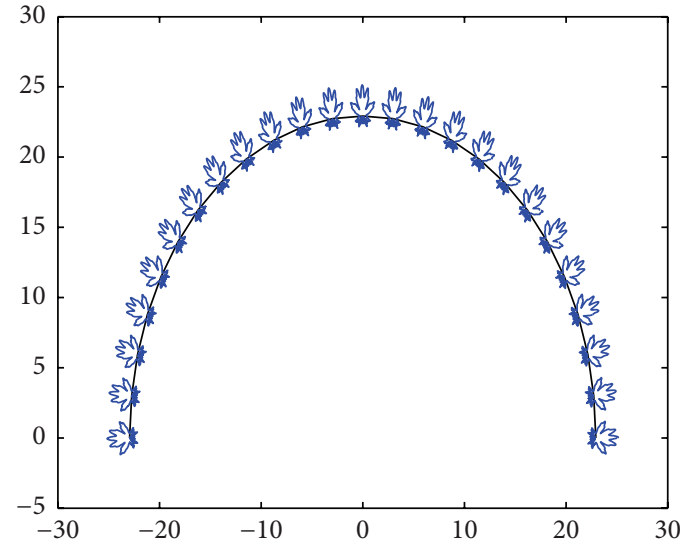

(a)

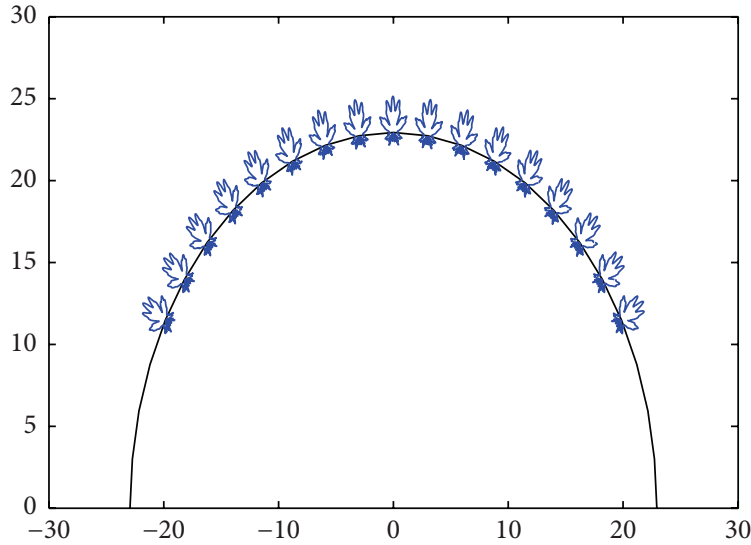

(b)

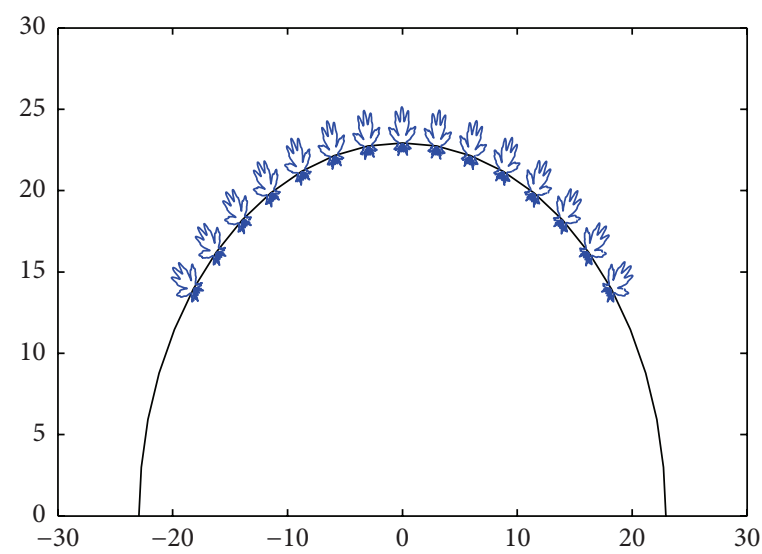

(c)

Figure 12: (a) All elements. (b) Active elements selection in Step 1. (c) Active elements selection in Step 2.

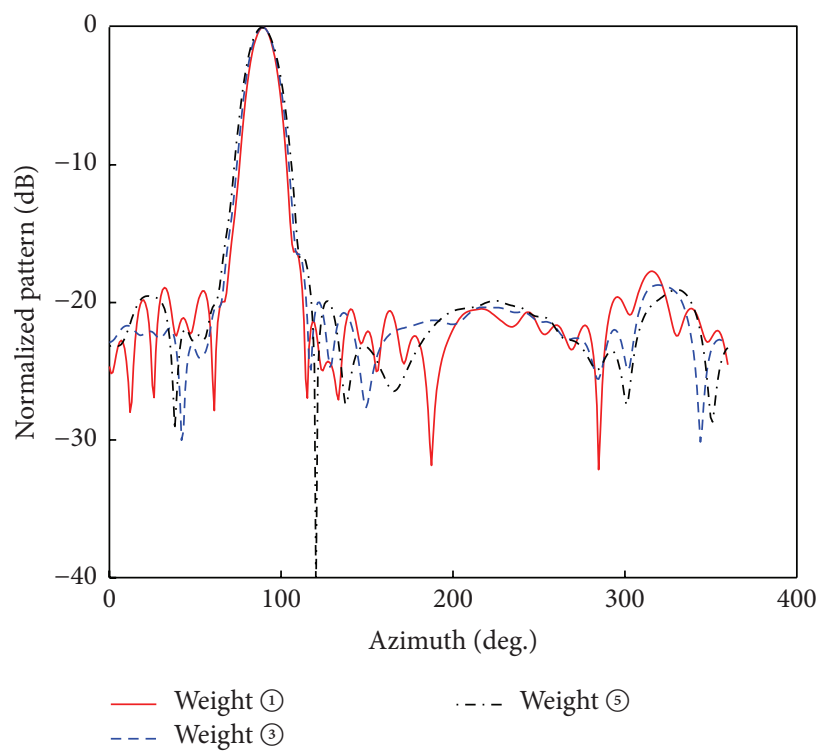

(a)

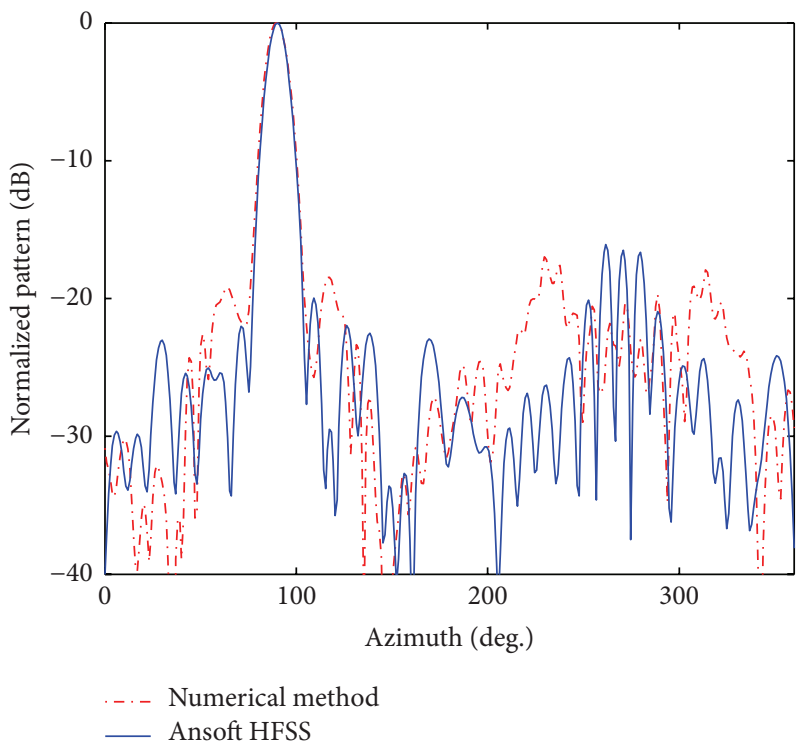

(b)

Figure 13: (a) Pattern synthesized by weight derived from weight (1), weight (3), and weight (5) in Table 4. (b) Comparison between Ansoft HFSS and numerical results. 
TABLE 4: Active elements selection process.

\begin{tabular}{|c|c|c|c|c|c|c|}
\hline Element sequence & $\begin{array}{c}\text { Phi }=90 \\
\text { weight (1) }\end{array}$ & $\begin{array}{c}\text { Step 1 } \\
\text { selection } \\
\text { weight (2) }\end{array}$ & $\begin{array}{c}\text { Step } 2 \\
\text { Reoptimization } \\
\text { weight (3) }\end{array}$ & $\begin{array}{c}\text { Step 1 } \\
\text { Selection } \\
\text { weight (4) }\end{array}$ & $\begin{array}{c}\text { Step } 2 \\
\text { Reoptimization } \\
\text { weight (5) }\end{array}$ & $\begin{array}{l}\text { Satisfy end } \\
\text { condition }\end{array}$ \\
\hline 1 & 0.0261 & - & - & - & - & - \\
\hline 2 & 0.0010 & - & - & - & - & - \\
\hline 3 & 0.0299 & - & - & - & - & - \\
\hline 4 & 0.0739 & - & - & - & - & - \\
\hline 5 & 0.1502 & 0.1502 & 0.0928 & - & - & - \\
\hline 6 & 0.2184 & 0.2184 & 0.1529 & 0.1527 & 0.1090 & 0.1090 \\
\hline 7 & 0.3324 & 0.3324 & 0.2562 & 0.2524 & 0.1973 & 0.1973 \\
\hline 8 & 0.4723 & 0.4723 & 0.4015 & 0.3935 & 0.3418 & 0.3418 \\
\hline 9 & 0.6027 & 0.6027 & 0.5494 & 0.5411 & 0.5108 & 0.5108 \\
\hline 10 & 0.7519 & 0.7519 & 0.7165 & 0.7121 & 0.7039 & 0.7039 \\
\hline 11 & 0.8832 & 0.8832 & 0.8578 & 0.8549 & 0.8549 & 0.8549 \\
\hline 12 & 1.0000 & 1.0000 & 0.9751 & 0.9773 & 0.9824 & 0.9824 \\
\hline 13 & 1.0000 & 1.0000 & 0.9883 & 1.0000 & 0.9919 & 0.9919 \\
\hline 14 & 1.0000 & 1.0000 & 0.9545 & 0.9828 & 0.9524 & 0.9524 \\
\hline 15 & 0.9170 & 0.9170 & 0.8551 & 0.8816 & 0.8073 & 0.8073 \\
\hline 16 & 0.7816 & 0.7816 & 0.6937 & 0.7278 & 0.6340 & 0.6340 \\
\hline 17 & 0.6192 & 0.6192 & 0.5397 & 0.5702 & 0.4537 & 0.4537 \\
\hline 18 & 0.4948 & 0.4948 & 0.3766 & 0.3999 & 0.2870 & 0.2870 \\
\hline 19 & 0.3306 & 0.3306 & 0.2421 & 0.2571 & 0.1666 & 0.1666 \\
\hline 20 & 0.2140 & 0.2140 & 0.1350 & 0.1456 & 0.0780 & 0.0780 \\
\hline 21 & 0.1289 & 0.1289 & 0.0766 & - & - & - \\
\hline 22 & 0.0520 & - & - & - & - & - \\
\hline 23 & 0.0291 & - & - & - & - & - \\
\hline 24 & 0.0010 & - & - & - & - & - \\
\hline 25 & 0.0207 & - & - & - & - & - \\
\hline
\end{tabular}

elements, and 15 elements are nearly the same, which means using only $60 \%$ of total elements can obtain nearly the same pattern from the whole array elements activated.

In order to validate the strategy proposed, full-wave electromagnetic calculation is executed using 15 active elements as shown in Figure 13(b). We can see that the array pattern obtained from Ansoft HFSS and numerical method is nearly the same, which demonstrates the accuracy and availability of our selection strategy.

\section{Conclusions}

In this paper, PSOGSA algorithm is efficiently applied to pattern synthesis and activated elements election for conformal array. The theory of PSOGSA algorithm is explained and simulated based on Bench function. By considering uncoupled and coupled element pattern, PSOGSA algorithm is applied in conformal pattern synthesis with numerical comparison and full-wave calculation. Then, an element selection strategy is proposed in conformal array with nearly the same radiation pattern. The results of numerical simulation and full-wave calculation demonstrate that PSOGSA algorithm has excellent ability of global optimum search for the conformal pattern synthesis and the active elements selection.

\section{Conflict of Interests}

The authors declare that there is no conflict of interests regarding the publication of this paper.

\section{References}

[1] J. Lars and P. Patrik, Conformal Array Antenna Theory and Design, John Wiley \& Sons, Hoboken, NJ, USA, 2006.

[2] O. M. Bucci, G. D. Elia, and G. Romito, "Power synthesis of conformal arrays by a generalized projection method," IEE Proceedings-Microwaves, Antennas and Propagation, vol. 142, no. 6, pp. 467-471, 1995.

[3] O. M. Bucci and G. D. Elia, "Power synthesis of reconfigurable conformal arrays with phase-only control," IEE Proceedings Microwaves, Antennas and Propagation, vol. 145, no. 1, pp. 131136, 1998.

[4] L. I. Vaskelainen, "Iterative least-squares synthesis methods for conformai array antennas with optimized polarization and fre- 
quency properties," IEEE Transactions on Antennas and Propagation, vol. 45, no. 7, pp. 1179-1185, 1997.

[5] P. N. Fletcher and M. Dean, "Least squares pattern synthesis for conformal arrays," Electronics Letters, vol. 34, no. 25, pp. 2363$2365,1998$.

[6] P. Y. Zhou and M. A. Ingram, "Pattern synthesis for arbitrary arrays using an adaptive array method," IEEE Transactions on Antennas and Propagation, vol. 47, no. 5, pp. 862-869, 1999.

[7] R. J. Allard, H. D. Werner, and P. L. Werner, "Radiation pattern synthesis for arrays of conformal antennas mounted on arbitrarily-shaped three-dimensional platforms using genetic algorithms," IEEE Transactions on Antennas and Propagation, vol. 51, no. 5, pp. 1054-1062, 2003.

[8] Z. Xu, H. Li, Q.-Z. Liu, and J.-Y. Li, "Pattern synthesis of conformal antenna array by the hybrid genetic algorithm," Progress in Electromagnetics Research, vol. 79, pp. 75-90, 2008.

[9] J. A. Ferreira and F. Ares, "Pattern synthesis of conformai arrays by the simulated annealing technique," Electronics Letters, vol. 33, no. 14, pp. 1187-1189, 1997.

[10] J. A. Ferreira and F. Ares, "Radiation pattern synthesis for conformal antenna arrays," Journal of Electromagnetic Waves and Applications, vol. 14, no. 4, pp. 473-492, 2000.

[11] M. M. Khodier and C. G. Christodoulou, "Linear array geometry synthesis with minimum sidelobe level and null control using particle swarm optimization," IEEE Transactions on Antennas and Propagation, vol. 53, no. 8, pp. 2674-2679, 2005.

[12] D. W. Boeringer and D. H. Werner, "Particle swarm optimization of a modified bernstein polynomial for conformal array excitation synthesis," in Proceedings of the 2004 IEEE Antennas and Propagation Society International Symposium Digest, vol. 3, pp. 2293-2296, 2004.

[13] R. Li, L. Xu, X.-W. Shi, N. Zhang, and Z.-Q. Lv, "Improved differential evolution strategy for antenna array pattern synthesis problems," Progress in Electromagnetics Research, vol. 113, pp. 429-441, 2011.

[14] G. G. Roy, S. Das, P. Chakraborty, and P. N. Suganthan, "Design of non-uniform circular antenna arrays using a modified invasive weed optimization algorithm," IEEE Transactions on Antennas and Propagation, vol. 59, no. 1, pp. 110-118, 2011.

[15] W. T. Li, X. W. Shi, Y. Q. Hei, S. F. Liu, and J. Zhu, "A hybrid optimization algorithm and its application for conformal array pattern synthesis," IEEE Transactions on Antennas and Propagation, vol. 58, no. 10, pp. 3401-3406, 2010.

[16] Y.-Y. Bai, S. Xiao, C. Liu, and B.-Z. Wang, "A hybrid IWO/PSO algorithm for pattern synthesis of conformal phased arrays," IEEE Transactions on Antennas and Propagation, vol. 61, no. 4, pp. 2328-2332, 2013.

[17] E. Rashedi, H. Nezamabadi-pour, and S. Saryazdi, "GSA: a gravitational search algorithm," Information Sciences, vol. 179, no. 13, pp. 2232-2248, 2009.

[18] M. Seydali and M. H. Siti, "A new hybrid PSOGSA Algorithm for function optimization," in Proceedings of the International Conference on Computer and Information Application (ICCIA '10), pp. 374-377, November 2010.

[19] W. S. Tan, M. Y. Hassan, H. A. Rahman, M. P. Abdullah, and F. Hussin, "Multi-distributed generation planning using hybrid particle swarm optimisation-gravitational search algorithm including voltage rise issue," IET Generation, Transmission and Distribution, vol. 7, no. 9, pp. 929-942, 2013. 

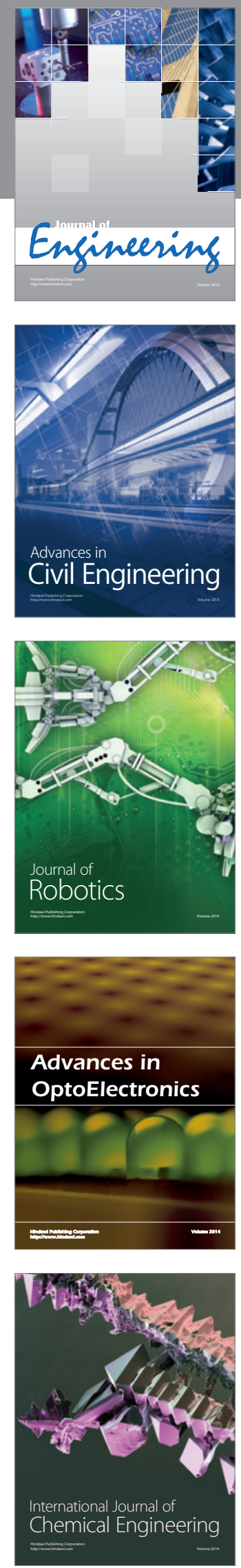

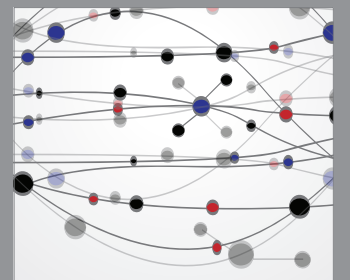

The Scientific World Journal
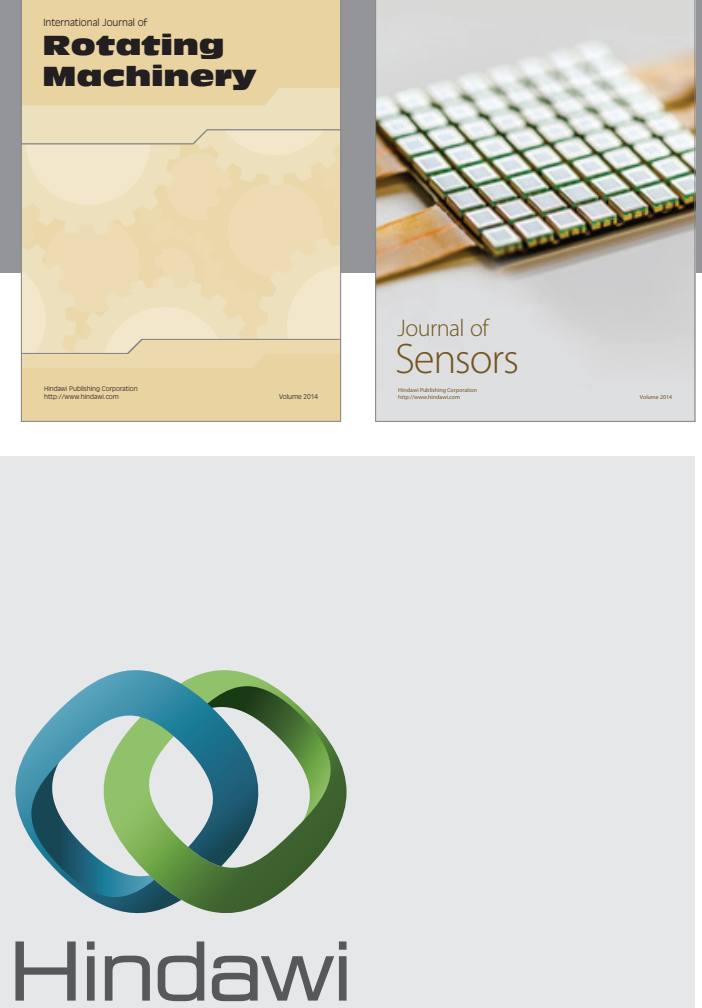

Submit your manuscripts at http://www.hindawi.com
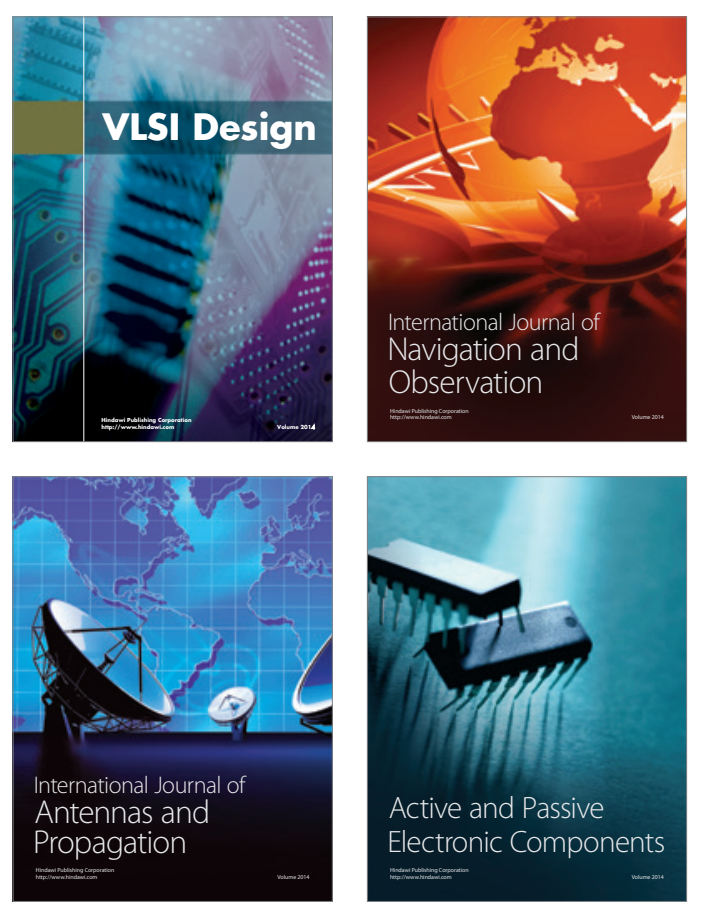
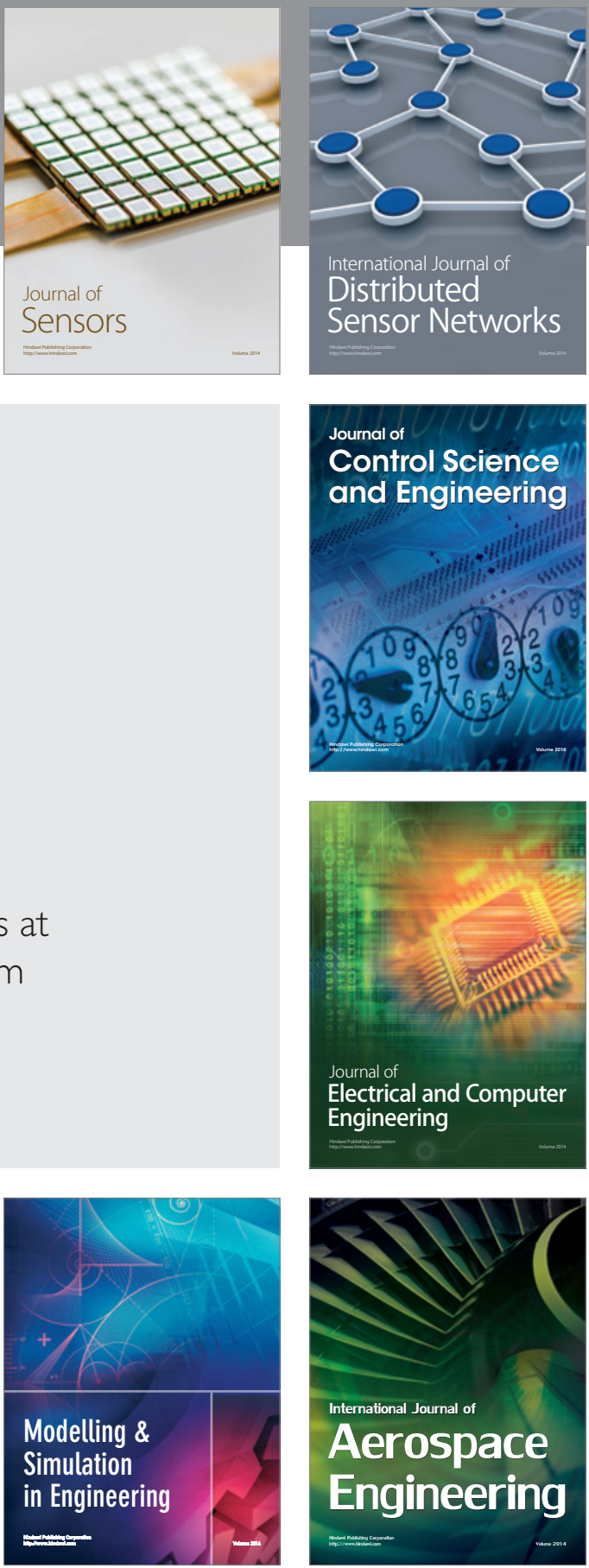

Journal of

Control Science

and Engineering
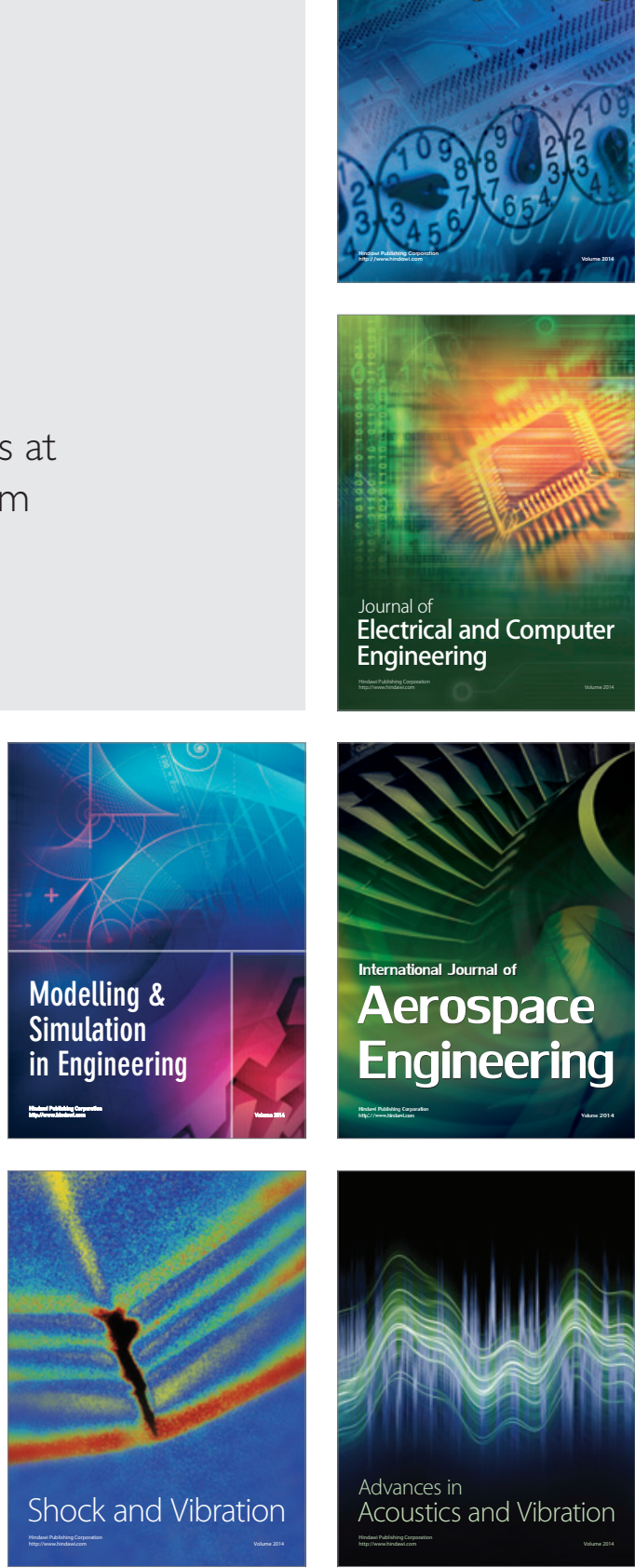